\title{
Design and Implementation of Arduino Microcontroller Based Automatic Lighting Control with I2C LCD Display
}

Akinwole 0O* and Oladimeji TT

Department of Electrical/Electronic Engineering, The Federal Polytechnic, Ado-Ekiti, Nigeria

\begin{abstract}
The project uses closed loop control system to automatically operate a lighting system. It employed Light Dependent Resistor LDR to sense the illumination level and compare the measured signal with the reference voltage realized through the usage of a potentiometer forming a potential divider. It highlights how an operational amplifier can be used as a comparator. This idea was transferred into Arduino Microcontroller. The latter is used to compare the signals using Arduino programming functions. The Arduino is multitasked using millis() to sound alarm at system switch-On or Reset. An $\mathrm{i} 2 \mathrm{C}$ is used to interface a Liquid Crystal Display with an advantage of using two analog pins A4 and A5 instead of four or eight $\mathrm{I} / \mathrm{O}$ pins for four and eight LCD modes respectively. The innovation will allow those $\mathrm{I} / \mathrm{O}$ pins dedicated to other tasks plus its attendant simplicity. The usage of $\mathrm{i} 2 \mathrm{C}$ scanner in identifying $\mathrm{i} 2 \mathrm{C}$ programming address as $0 \times 3 \mathrm{~F}$ is explained. The step by step explanation of Arduino codes is an asset. The paper recommends among others further improvement in the display interactivity through robust programming. An alarm could also be made to sound at each switch- over. It is believed that its simplicity will encourage its mass production with its attendant socio economic benefits.
\end{abstract}

Keywords: Arduino; Microcontroller; Programming; Comparator; LCD; Lighting

\section{Introduction}

A control system can be defined as an interaction of components in order to form a system configuration which is required to produce a desired system response. While an Open loop control system has no feedback, a closed loop system has a feedback thus earning it the appellation of a feedback control system [1]. The latter is employed in automatic control of controlled variable. So it does not depend on an operator, a desired input is selected as reference, the output situation is sensed by a sensor, itself produces commensurate electrical signal which is compared with the signal generated by the reference input. A comparator compares the two signals; the resultant is the error signal that drives a controller which in turn controls the output. In order words, the error signal is fed to the controller to reduce the error and desired output is obtained [1]. In this case, the illumination of the environment is to be controlled, the sunlight illuminates the environment in the daytime while at night an automatic control system takes over to actuate a switch which switches on the light. The system is independent of an operator or the house owner. The issue of forgetfulness of an operator will not arise.

\section{Microcontroller}

Nowadays, systems that have microcontrollers within them are common. They range from fans, TV remote controllers, Incubators to air-conditioning systems. There is widespread craves for these items by consumers due to their easy to control capabilities and compactness. Thus, hardly would you have electronic items in the house without microcontrollers.

A microcontroller is a small computer on a chip, unlike a microprocessor, it comprises processor, memory locations to store and execute programs. Apart from this, it consists of input and output ports to receive instructions and communicate with the outside world respectively [2]. A programmer programs microcontroller in high level language and a compiler compiles it and turn the instructions to low level machine language that can be understood by the controller. Computer understands ones and zeros, that is, two levels of HIGH (1) and LOW (0) which are binary digits.
A compiled program written for a microcontroller on its IDE is expected to be downloaded into its ROM using a Programmer.

\section{Methodology}

The design project was consummated by highlighting the problems to be solved and an algorithm was spelt out to realize the solution. This was also buttressed using a flowchart thus simplifying the writing of the Arduino source codes. The inputs to the analog is never digital but analog, this allows the choice of functions to read the analog signals that changes from $0 \mathrm{~V}$ to $+5 \mathrm{~V}$ depending on the level of illumination and voltage reference set. And if statement is copiously used, it is followed by an else statement, which executes when the expression is false [3]. An i2C scanner was downloaded online for the determination of its address. Maximum output current for the Microcontroller is 20 $\mathrm{mA}$ hence there was a need to have a transistor switch to drive a relay which switches the Lighting units [4].

\section{Arduino microcontroller}

The ubiquitous application of microcontroller in automobiles, robotics and industrial system has made its studies important. An Arduino board has a microcontroller and other extras that make its programming and debugging easy (Figure 1). An engineer just need to install an Arduino IDE which is downloadable online on his computer from www.arduino.cc, write the program, compile it and load it into the board [4]. No need for a separate programmer that costs extra money. Its functions are easy to understand, a gesture which makes it ideal for prototyping by inventors. An Arduino uses C programming language [3].

*Corresponding author: Akinwole OO, Department of Electrical/Electronic Engineering, The Federal Polytechnic, Ado-Ekiti, Nigeria, Tel: 2348062919293; E-mail: oyeakin2003@yahoo.com

Received March 21, 2018; Accepted May 18, 2018; Published May 23, 2018

Citation: Akinwole OO, Oladimeji TT (2018) Design and Implementation of Arduino Microcontroller Based Automatic Lighting Control with I2C LCD Display. J Electr Electron Syst 7: 258. doi: 10.4172/2332-0796.1000258

Copyright: (c) 2018 Akinwole OO, et al. This is an open-access article distributed under the terms of the Creative Commons Attribution License, which permits unrestricted use, distribution, and reproduction in any medium, provided the original author and source are credited. 


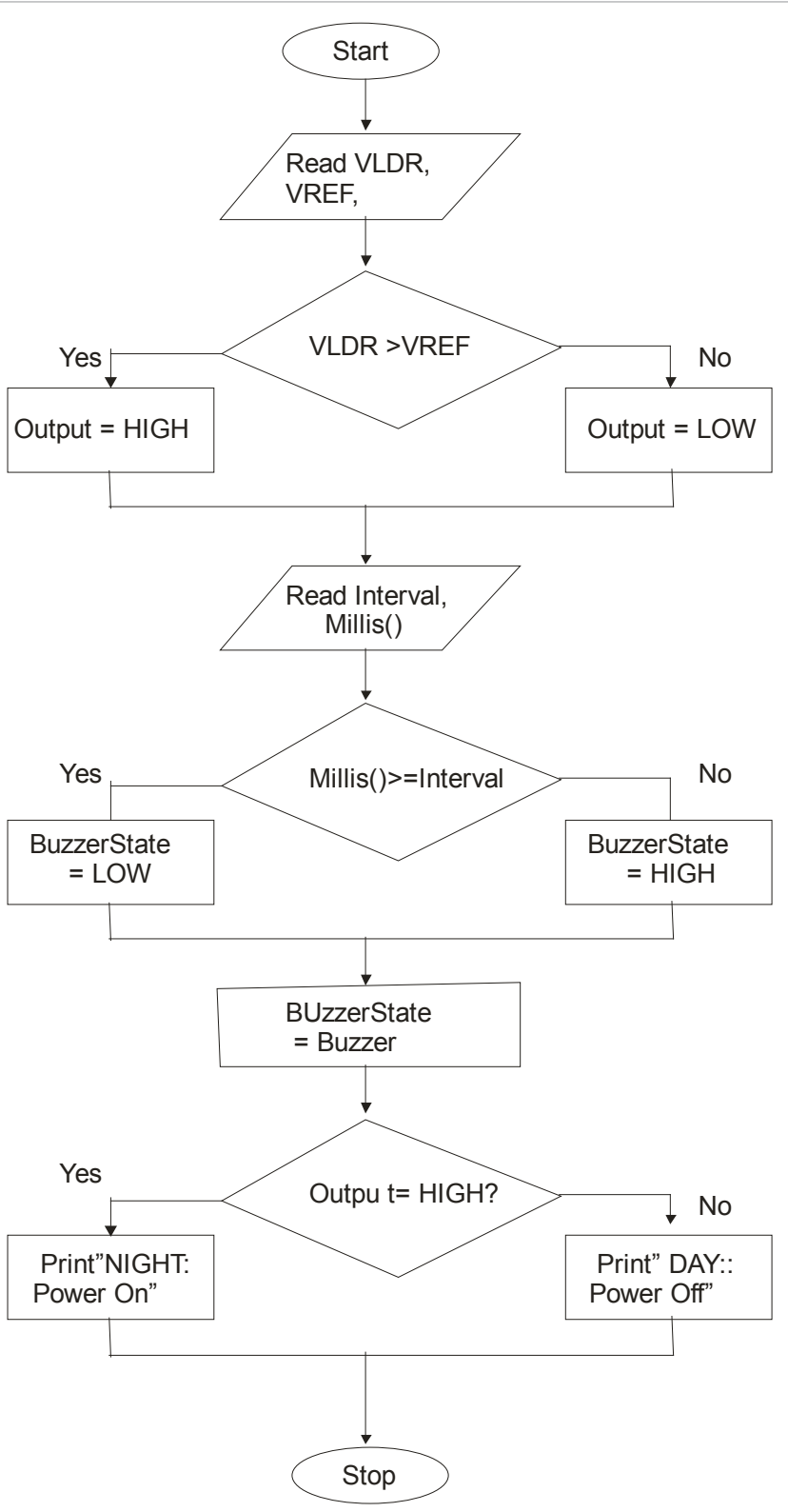

Figure 1: The system flowchart.

\section{Algorithms and flowcharting}

The following are the algorithms that list the sequence of steps needed to describe the solution to the design problem while the flowchart diagrammatically represents the order and interaction of activities and decisions [5].

Step 1: Read the values of $\mathrm{V}_{\mathrm{LDR}}$ and $\mathrm{V}_{\mathrm{REF}}$

Step 2: If the value of $\mathrm{V}_{\mathrm{LDR}}>\mathrm{V}_{\mathrm{REF}}$ output pin go HIGH $(+5 \mathrm{~V})$ else LOW (0V)

Step 3: BuzzerState=HIGH HIGH.

Step 4: If millis()>=Interval(mS), BuzzerState should go LOW, else

Step 5: Implement the BuzzerState
Step 6: If Outpin=HIGH, Print "NIGHT: Power On" else Print "DAY: Power Off."

\section{Arduino structures}

The project uses the simplest Arduino board referred to as Arduino Uno (Figure 2) [4]. It is a small microcontroller board. In this case an Atmega 328 that has 28 pins is used. Some of the components surrounding it are voltage regulator, reset button and Crystal oscillator; they allow the board to communicate with the computer without separate programmer. In order to enhance connections with the board, there are fourteen I/O pins; each pin is used as Input or Output pin depending on the specification in the codes written in the IDE. Also, there are six other analog input pins, A0 to A5, they take in Analoque quantity and convert them into a number between 0 and 1023. In the same vein, pins $3,5,6,9,10$ and 11 ; though are digital can be programmed as analogue output pins depending on the codes written in the IDE.

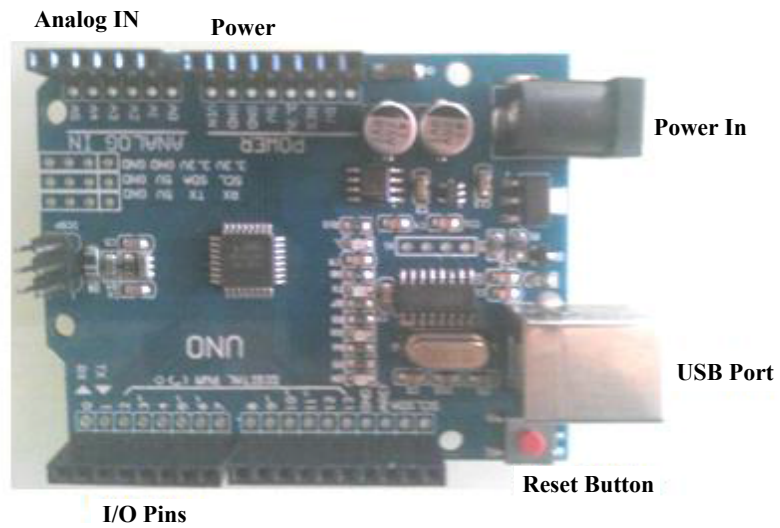

Figure 2: The arduino uno card.

An engineer can power the board from the computer USB port and can as well do that from a $9 \mathrm{~V}$ battery wiring the tip of the plug as positive terminal. Regulated $+5 \mathrm{~V}$ terminals points and grounds are added on the board for easy connections to other external circuitries.

\section{Voltage comparator}

A voltage comparator compares two signals and produces an output based on which of the two is greater. Typical examples of comparator Operational Amplifiers (Op-Amps) are LM 311 and LM339. The output produced is either positive (HIGH) or Negative (LOW) saturation according to the difference of the input voltages [6].

Two potential dividers are employed, one is formed from Light Dependent Resistor LDR and Resistor R1 as in Figure 3 and other is formed by a variable resistor VR1 and R2. The variable is set in order to provide reference voltage depending on the level of darkness needed to switch on the light. The light sensor LDR senses the illumination (Controlled variable); its resistance at darkness is very high, about 10 $\mathrm{M} \Omega$ and about $100 \Omega$ at light.

\section{Arduino UNO based voltage comparator}

An Arduino Uno Microcontroller armed with a well written code will perform the task indicated for a comparator. In this project Figure 4 Analog pins A0 and A1 are used. The output of the potential divider formed by the LDR and Resistor R 1 is connected to A0 and the Output, slider terminal of potentiometer which represent the voltage reference is connected to A1. The two signals are compared using an if-else statements after being read by analogRead () function. 


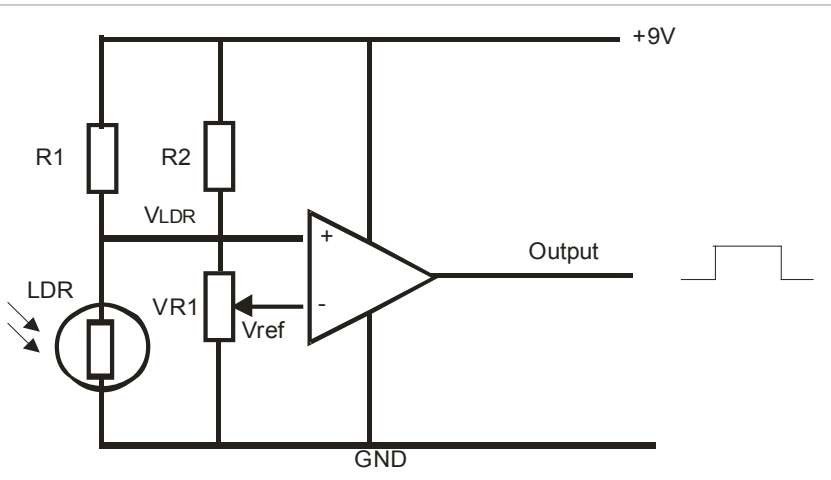

Figure 3: LDR and potentiometer driving an op amplifier connected as a comparator.

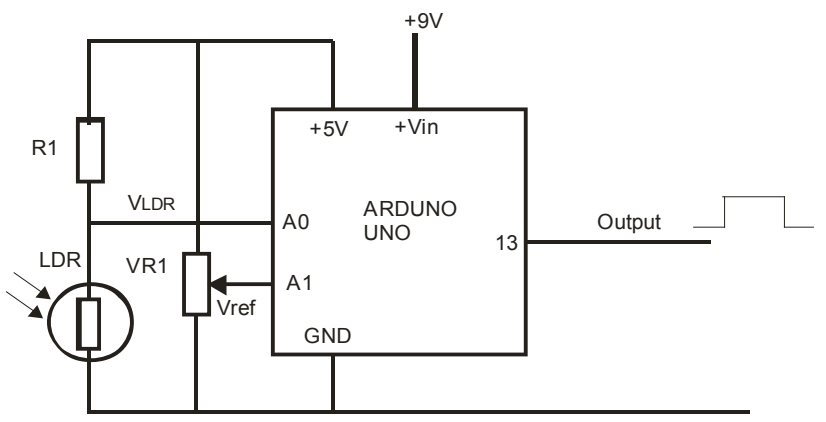

Figure 4: An arduino uno based comparator.

val1 $=\operatorname{analog} \operatorname{Read}(0)$;

$\operatorname{val} 2=\operatorname{analog} \operatorname{Read}(1)$

//check which is greater

if(val1>val2)\{digitalWrite(LED,HIGH);

else\{digitalWrite(LED,LOW); //Turn LED off\}

An analogRead(0) function reads A0, analogRead(1) reads A1 and assigned their values to Vall and Val2 respectively. So if val 1 is greater than val 2, there is darkness; then digitalWrite the output terminal named LED HIGH with the statement: digitalWrite(LED,HIGH). If not, that is val2>vall (Daylight), digitalWrite the output LOW using digitalWrite(LED,LOW). The low and high levels are $0 \mathrm{~V}$ and $+5 \mathrm{~V}$ respectively. The high level will be used to actuate a transtor switch which has a relay operating coil as its load. The relay normally open contact will be employed to switch on the lighting units.

\section{Alarm using millis () function}

This is a function that returns number of milliseconds Arduino has been up running, it overflows after about 50days, that is, returns to zero [7-9]. The syntax is millis(). It is used in this sketch to sound an alarm each time the device is reset or switched on. Already, an interval of $1000 \mathrm{mS}$ has been declared as an integer constant; while initial state of the buzzer has been fixed HIGH. So at switch ON there is HIGH Buzzer state.

if ( millis ( ) > = in terval) $\{$ buzzerStat e $=\mathrm{LOW}$; $\}$ else $\{$ buzzerState $=\mathrm{HIGH}$; digitalWrite(BUZZER, buzzerState);

When the millis() is greater than or equal to the interval declared, the buzzerState becomes LOW, if not it becomes HIGH. The latter state of $\mathrm{HIGH}$ produces a $\mathrm{HIGH}$ value of $+5 \mathrm{~V}$ to the piezo electric device which sounds an alarm. The moment the condition of IF statement is met, buzzerState becomes LOW thus stopping the alarm. A digitalWrite statement: digitalWrite(BUZZER, buzzerState) writes buzzerState (HIGH or LOW) to BUZZER pin. In this project, the buzzer is connected to an I/O pin 7.

\section{Liquid Crystal Display (LCD)}

Parallel LCD modules have pin outs that are the same. They have eight data pins D0-D7. If four pins (D4-D7) are used, it is called 4-pin mode and when all are utilized, the connection is being referred to as 8 pin mod. For obvious reason, engineers use 4-pin method. There are pins on the LCD for enabling display that is EN. RW pin is normally employed for setting Read/Write. VSS and VDD pins are for ground and $+5 \mathrm{~V}$ respectively. RS is used to select the register. Backlight LED has two terminals, one for the anode and the other is the cathode.

VO pin allow contrast adjustment using potentiometer [10]. The syntax is:

Liquid Crystal LCD (RS,EN,D4,D5,D6,D7); to connect to an Arduino Uno, the statement is

Liquid Crystal LCD $(2,3,4,5,6,7)$;

Here, Arduino I/O pins 2,3,4,5,6,7 are connected to RS,EN,D4,D5,D6 and D7 respectively.

\section{I2C Liquid Crystal Display}

In this project, an $\mathrm{i} 2 \mathrm{C}$ interface was used to interface Arduino Uno to the LCD. It allows only two analog pins A4 and A5 to be used. I/O Pins 2,3,4,5,6,7 on Arduino can be used for other tasks. Another advantage is that one can connect more $\mathrm{i} 2 \mathrm{C}$ devices on the same two analog pins to drive their LCDs. The I2C circuit board is compatible to various LCDs like $6 \times 2$ or $20 \times 4$. In this case, the microcontroller was connected thus:

- $\quad+5 \mathrm{~V}$ on $\mathrm{i} 2 \mathrm{C}$ was connected to $+5 \mathrm{~V}$ on the Arduino

- GND to Ground

- $\quad$ SDA to Data line A4

- $\quad$ SCK on i2C to Clock A5.

\section{I2C scanner}

The code for initializing LCD with i2C interface was LiquidCrystal I2C lcd $(0 \times 3 \mathrm{~F}, 2,1,0,4,5,6,7)$. The address of the i2 $\mathrm{C}$ device is $0 \times 3 \mathrm{~F}$. I2C scanner scans the connection and returns $0 \times 3 \mathrm{~F}$. The software was downloaded online from (www.playground.arduino.cc). The code was copied and pasted on the IDE while the project is connected to the PC USB port COM 8. From the IDE Menu, tools was selected and Serial Monitor opened. The window indicated $0 \times 3 \mathrm{~F}$ as the address of the $\mathrm{i} 2 \mathrm{C}$ interface module thus: $\mathrm{I} 2 \mathrm{C}$ device found at address $0 \times 3 \mathrm{~F}$.

\section{Project wiring}

The project was wired on a breadboard as shown in the Figure 5 below. The threshold of switching was set using the potentiometer in the potential divider which has its output feeding Arduino analog pin A1. As a flashlight is directed to the LDR, the LED switches off thus indicating day while LCD display displaying DAY: POWER OFF. When the light from the flashlight is off, the LED comes on together with the LCD display showing NIGHT: POWER ON. 


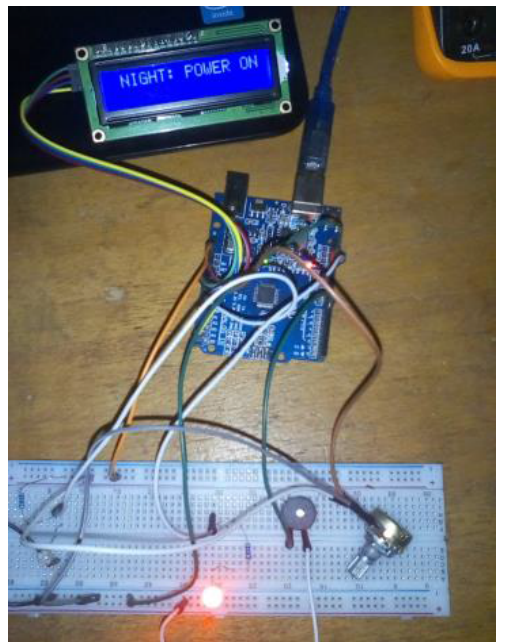

Figure 5: Wiring of the arduino project.

\section{Codes}

\#include <LiquidCrystal_I2C.h>

\#include $<$ Wire.h $>$

LiquidCrystal_I2C $\operatorname{lcd}(0 \times 3 \mathrm{~F}, 2,1,0,4,5,6,7)$;

const int $\mathrm{LED}=13$;

const int BUZZER=7;

int buzzerState $=\mathrm{HIGH}$;

int vall $=0$; // to store state value of $\mathrm{LDR}$

int val2=0; //to store the value of VREF

unsigned long interval $=1000$;

void setup() \{lcd.begin(16,2); // for $16 \times 2$ LCD module

lcd.setBacklightPin(3,POSITIVE);

lcd.setBacklight(HIGH);

lcd.home();//go home

lcd.print(“AUTOMATIC LIGHT”);

lcd.setCursor(2,1);

lcd.print(“CONTROLLER”);

pinMode(LED,OUTPUT);

pinMode(BUZZER,OUTPUT);

//Note analog pins are automatically set as input\}

void $\operatorname{loop}()\{\operatorname{val} 1=\operatorname{analogRead}(0) ; \quad \operatorname{val} 2=\operatorname{analogRead}(1) ; \quad / /$ check which is greater,

if(val1>val2)\{digitalWrite(LED,HIGH);\}

else\{digitalWrite(LED,LOW); //Turn LED off\}

if $($ millis ()$>=$ interval $)\{$ buzzerState=LOW;

else $\{$ buzzerState $=\mathrm{HIGH} ;\}$

digitalWrite(BUZZER,buzzerState);delay(1000); if $($ digitalRead(LED)=HIGH $)\{$ lcd.clear();lcd.setCursor(1,0);lcd . print(“NIGHT: POWER ON”);\} OFF");\}

else\{lcd.clear();lcd.setCursor(1,0);lcd.print(“ $\quad$ DAY: POWER

\section{Conclusion and Recommendations}

The project has succeeded in showing simplicity in the use of Arduino in prototyping and designs of intelligent and embedded systems. The advantage of programming a microcontroller without a programmer coupled with the ease of debugging Arduino codes is an asset. In order to control lighting systems and other bigger loads with higher power expected to draw higher currents. Figure 6 a bipolar switching transistor or MOSFET driven relay can have its normally opened contact connected in series with the controlled lighting units. In a situation where the current rating of the relay's contact set is not enough, the latter can be connected in series with the operating coil of a contactor while the load, that is, the lighting load connected in series with its normally open poles. MOSFET is being suggested being voltage operated, with very high input impedance can be driven directly by Arduino I/O pins.

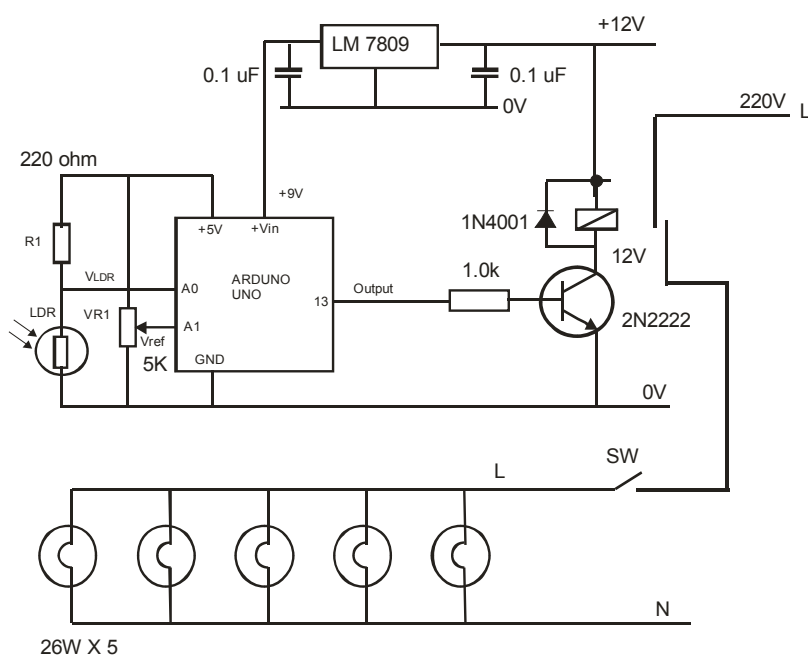

Figure 6: Complete circuit diagram of the design.

Ideas and functions used in this project can as well be employed in other equipment which has been hitherto designed with analog approach or other traditional microcontrollers.

Here are other recommendations made:

- Improvement can be made on display programs to allow interactive sessions with the user.

- Tone can be programmed to sound momentarily for a short period of time to alert the user on each transition that is, switching on the lighting units and their switching off.

\section{References}

1. Ahamed SK, Sarkar A, Mitra M, Sengupta S (2012) Detection of induction motor broken bar fault through envelops analysis using start-up current. Procedia Technology 4: 646-651.

2. Boughrara K, Takorabet N, Ibtiouen R, Touhami O, Dubas F (2015) Analytica analysis of cage rotor induction motors in healthy, defective and broken bars conditions. IEEE Trans Magn 51: 1-17.

3. Salem SB, Bacha K, Chaari A (2012) Support vector machine based decision 
Citation: Akinwole OO, Oladimeji TT (2018) Design and Implementation of Arduino Microcontroller Based Automatic Lighting Control with I2C LCD Display. J Electr Electron Syst 7: 258. doi: 10.4172/2332-0796.1000258

Page 5 of 5

for mechanical fault condition monitoring in induction motor using an advanced Hilbert-Park transform. ISA Transactions 51: 566-572.

4. Henao H, Bruzzese C, Strangas E, Pusca R, Estima J, et al. (2014) Trends in fault diagnosis for electrical machines: A review of diagnostic techniques. IEEE Ind Electron M 8: 31-42.

5. Naha A, Samanta AK, Routray A, Deb AK (2016) A method for detecting halfbroken rotor bar in lightly loaded induction motors using current. IEEE Trans Instrum Meas 65: 1614-1625.

6. Siddiqui KM, Sahay K, Giri V (2015) Rotor broken bar fault detection in induction motor using transformative techniques. J Electr Eng 15: 135-141.

7. Costa CDa, Kashiwagi M, Mathias MH (2015) Rotor failure detection of induction motors by wavelet transform and Fourier transform in non-stationary condition. Case Studies in Mechanical Systems and Signal Processing 1: 15-26.

8. Pires VF, Kadivonga M, Martins J, Pires A (2013) Motor square current signature analysis for induction motor rotor diagnosis. Meas 46: 942-948.

9. Xu B, Sun L, Xu L, Xu G (2013) Improvement of the Hilbert method via ESPRIT for detection rotor fault in induction motors at low slip. IEEE T ENERGY CONVER 28: 225-233.

10. Garcia-Perez A, Romero-Troncoso RDJ, Cabal-Yepez E, Osornio-Rios RA (2011) The application of high-resolution spectral analysis for identifying multiple combined faults in induction motors. IEEE T Ind Electron 58: 20022010. 